\title{
K12 ve Lisans Öğrencilerinin Endüstri 4.0 Kavramına İlişkin Algıları
}

\author{
Hatice Hicret ÖZKOÇ, Halit KARALAR*
}

\author{
K12 ve Lisans Öğrencilerinin Endüstri 4.0 Kavramına \\ İlişkin Algıları
}

Özet

$\mathrm{Bu}$ araştırmanın amacı, K12 ve Lisans öğrencilerinin Endüstri 4.0 kavramına ilişkin algılarını metaforlar yardımıyla belirlemektir. Olgubilim deseninde yürütülen araştırmaya 139 öğrenci (49 K12, 90 Lisans) katılmıştır. Araştırma verileri araştırmacılar tarafından geliştirilen bir form ile toplanmış ve elde edilen veriler içerik analizi ile analiz edilmiştir. Araştırma sonucunda, K12 öğrencilerinin Endüstri 4.0 kavramını 48 metafor ile açıkladıkları, bu metaforların iki ana tema altında toplandığı ve görüşlerin genel olarak olumlu olduğu görülmüştür. Diğer taraftan Lisans öğrencilerinin 89 metafor ile Endüstri 4.0 kavramını açıkladıkları, bu metaforların iki ana tema altında toplandığı ve görüşlerin genel olarak olumsuz olduğu sonucuna ulaşılmıştır. Araştırmada öğrenciler arasındaki görüş farklılığın nedenleri tartışımış ve uygulamaya dönük önerilere yer verilmiştir.

Anahtar Kelimeler: Endüstri 4.0, Lisans Öğrencileri, K12 Öğrencileri, Metafor, Algı

\author{
K12 and Undergraduate Students' Perceptions on \\ Industry 4.0
}

\section{Abstract}

The aim of this research was to determine the perceptions of $\mathrm{K} 12$ and Undergraduate students about Industry 4.0 concept by metaphors. 139 students (49 K12, 90 Undergraduate) participated in the research conducted in the phenomenology design. The research data were collected with a form developed by the researchers and were analyzed by content analysis. As a result of the research, it was seen that K12 students explained Industry 4.0 concept with 48 metaphors, these metaphors were gathered under two main themes and the opinions were generally positive. On the other hand, it was concluded that Undergraduate students explain Industry 4.0 concept with 89 metaphors, these metaphors are gathered under two main themes and the opinions are generally negative. In the research, the reasons of the difference between the students were discussed and practical suggestions were given.

Key Words: Industry 4.0, Undergraduate Students, K12 Students, Metaphor, Perception

\section{Giriş}

Son yıllarda siyasi temelli konular dışında, tüm küresel platformlarda ve iş dünyasında öne çıkan konulara bakıldığında, iklim değişikliği ve sürdürülebilirlik ile birlikte bilişim teknolojilerinin ve Endüstri 4.0'ın oldukça ön plana çıktığı görülmektedir (Fırat ve Fırat, 2017). Davos'ta her yıl geleneksel olarak düzenlenen ve küresel ekonomiye yön veren Dünya Ekonomik Forumu'nun 2016 yılı ana teması Endüstri 4.0 olmuştur.

\footnotetext{
*Hatice Hicret ÖZKOÇ, Doç. Dr., Muğla Sıtkı Koçman Üniversitesi, İktisadi ve İdari Bilimler Fakültesi, İşletme Bölümü, hatice.ozkoc@mu.edu.tr; ORCID ID orcid.org / 0000-0003-0037-4603, Halit KARALAR, Dr. Öğr. Üyesi, Muğla Sıtkı Koçman Üniversitesi, Eğitim Fakültesi, Bilgisayar ve Öğretim Teknolojileri Eğitimi Bölümü, halit@mu.edu.tr, ORCID ID orcid.org / 0000-0001-9344-9672
} 
Birinci endüstri devrimi yaklaşık olarak 1840 'I yıllara kadar sürmüştür. Demiryolların inşası ve buhar makinesinin devreye girmesiyle beraber mekanik üretimin yoğunlaştığı bir süreç yaşanmıştır. 20.yy ile birlikte ikinci endüstri devrimi gerçekleşmiş; elektrik ve montaj hatlarının kullanımı ile birlikte bu dönemde seri üretimlere geçilmiştir. 1970'lerde başlayan üçüncü endüstri devrimi ile birlikte yarı iletkenler, sunucu bilgisayarlar ve kişisel bilgisayarlar yaygınlaşmış ve İnternet günlük hayata dahil olmaya başlamıştır. Bu gelişmelere bağlı olarak üçüncü endüstri devrimi bilgisayar devrimi ya da dijital devrim olarak da adlandırımaktadır. Bütün bu sanayi devrimleri, yalnızca üretimin kendisini değil, aynı zamanda işgücü piyasasını ve eğitim sistemini de etkilemiştir. Bu değişikliklerin bir sonucu olarak bazı meslekler ve işler ortadan kalkmış ve yeni meslek grupları ortaya çıkmıştır.

2008 yılında yaşanan küresel krizin ardından gelişmiş ülkeler yeniden bir arayış içine girmişler ve endüstrileşme hareketine başlamışlardır. Bu ülkeler hali hazırda kullanılan imalat yöntemleri ve teknolojileri üzerinde iyileştirmeler yapmak yerine inovasyona ağırlık vermişler ve bilişim teknolojilerini imalatta uygulama üzerine odaklanmışlardır (Fırat ve Fırat, 2017). Bu açıdan, Endüstri 4.0 ismi ileri sanayi devrimine atıfta bulunmaktadır. Oysa ilk üç endüstri devrimi ise mekanizasyon, elektrik ve bilişim teknolojileri ile ortaya çıkmıştır (Gilchrist, 2016: 195).

Endüstri 4.0'ın temeli esasında Alman üretiminin merkezinde yer almaktadır. 2011 yılında Alman hükümeti tarafından adlandırılan Endüstri 4.0 konusunda Alman Ulusal Bilim ve Mühendislik Akademisi tarafından bir manifesto yayınlanmış ve bu manifesto büyük ilgi görmüştür. Dünya Ekonomik Forumu Kurucusu olan Klaus Schwab, Endüstri 4.0'ın üçüncü endüstri devriminin bir devamı olmadığını açıklamakta ve Endüstri 4.0'ın ortaya çıkışını üç temel nedene bağlamaktadır. Schwab (2016) tarafından belirtilen bu nedenler şöyledir: (1) Hız: Schwab’a göre bu devrim doğrusal olarak değil üstel bir hızda ilerlemektedir. Birbiriyle bağlantılı ve çok yönlü olan yeni teknoloji birbirini tetikleyerek hızı bir şekilde gelişmekte ve daha yetenekli teknolojilerin önünün açılmasına neden olmaktadır. (2) Genişlik ve Derinlik: Bu devrim dijital devrimin üzerinde yükselmekte ve ekonomide, iş dünyasında, toplumda ve bireysellikte benzeri görülmedik paradigma değişimlerine götüren çok çeşitli teknolojileri bir araya getirmektedir. Schwab iktisadi sorular olan "ne" ve "nasıl" soruları ile birlikte "biz kimiz" sorusunun da bu süreçte değişmekte olduğunu ifade etmektedir. (3) Sistem etkisi: Schwab’a göre Endüstri 4.0 sonucunda bütün sektörler, şirketler ve hatta ülkeler olarak bütünsel bir değişim yaşanması olasıdır.

Endüstri 4.0 çok geniş yelpazede pek çok kavramı içermektedir (Lasi, Fettke, Kemper, Feld ve Hoffmann, 2014). Bu kavramlar, 3D yazıcılar, bulut teknolojiler, siber güvenlik, sensörler, otonom robotlar, arttırılmış gerçeklik, yatay ve dikey sistem entegrasyonu, simülasyonlar, eklemeli üretim, nesnelerin interneti, büyük veri ve analitiklerdir (Boston Consulting Group, 2015; Fırat ve Fırat, 2017). Endüstri 4.0 döneminde endüstriyel ürünlerin üretiminde kullanılacak en önemli dokuz teknoloji ise Şekil 1'de görüldüğü gibidir. 
Diğer taraftan, Endüstri 4.0 fiziksel ve dijital birçok yapının üzerinde yükselmektedir. Fiziksel olarak bakıldığında akıllı fabrikaların kurulması, siber-fiziksel sistemlerin geliştirilmesi, özerk taşıtların piyasaya sürülmesi, ileri robotik uygulamaların kullanımı ve 3D yazıcıların yaygınlaşması önemli itici kuvvetler olarak karşımıza çıkmaktadır. Dijital olarak ise nesnelerin internetinin yaygınlaşması ve dijital para birimlerinin ortaya çıkması bu devrimi daha da sağlamlaştırmaktadır (Schwab, 2016; Lasi vd., 2014).

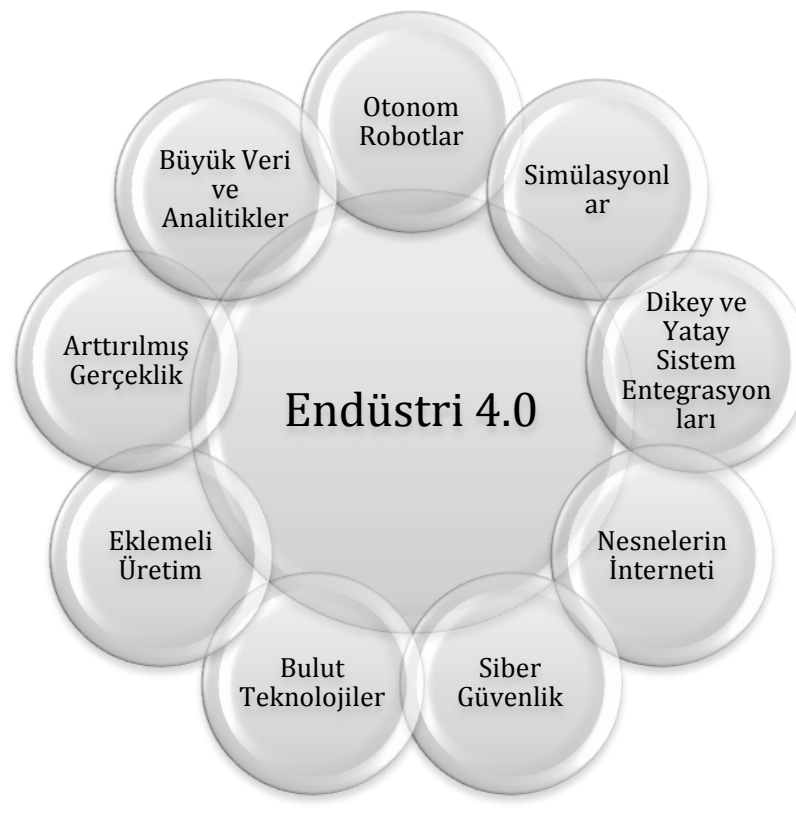

Şekil 1. Endüstri 4.0 Döneminde Ürünlerin Üretiminde Kullanılacak 9 Teknoloji (Boston Consulting Group, 2015)

Bilim kurgu filmlerinde görülen pek çok teknoloji günümüzde gerçeğe dönüşmüştür. Örneğin, 3D yazıcılar ile gelinen noktada küresel moda endüstrisinin dengeleri değişmiş ve bu sektörün geleceği tartışmalı hale gelmiştir. Öte yandan eklemeli üretim ve malzeme mühendisliği ile sentetik biyoloji birleşmiş ve mikroorganizmalar içeren ürünler geliştirilmiştir. Hemen her alandan bu tür gelişmelerin ve değişmelerin artan bir biçimde yaşandığı dikkate alınırsa geleceğin yetişkinlerinin bu anlamda donanımlı olmaları göz ardı edilemeyecek derecede önemlidir.

Endüstride yaşanan devrimler toplumsal yapıda dönüşüme neden olmakta, toplumsal yapıdaki dönüşüm de eğitimi yakından etkilemektedir. Tarım toplumundan sanayi topluma geçişle birlikte günümüz okul sisteminin temellerinin atıldığı düşünüldüğünde, Endüstri 4.0 ile birlikte hem toplumsal yapıda hem de eğitimde önemli değişimlerin olacağı kaçınılmazdır. 
Hatice Hicret ÖZKOÇ | Halit KARALAR

Özellikle son beş yıl içerisinde Endüstri 4.0 ile ilgili dünya genelinde yapılan çalışmalar oldukça fazlalaşmış ve çeşitlenmiştir. İmalat sanayi ve üretim sistemleri (Zheng, 2018; Qi ve Tao, 2018; Theorin vd., 2017), lojistik (Lin ve Yang, 2018; Hofmann ve Rüsch, 2017), pazarlama (Jazdi, 2014; Saldivar, Goh, Chen ve Li, 2016) ve nesnelerin interneti (Xia, Yang, Wang ve Vinel, 2012; Jeschke, Brecher, Meisen, Özdemir ve Eschert, 2017; Wan, Tang, Hua, Li ve Lloret, 2018) gibi konularda günümüzde pek çok akademisyen yoğun bir biçimde çalışmaya devam etmektedir. Türkiye'de konuyla ilgili yapılan çalışmalara bakıldığında istihdam (Öcal ve Altıntaş, 2018; Koca, 2018; Topkaya, 2016), girişimcilik (Soylu, 2018; Saatçi, 2017), ekonomik etkileri (Özkan, Al ve Yavuz, 2018; Bulut ve Akçacı, 2017) ve mobilyacılıkta oluşan değişimler (Öztürk ve Koç, 2017; Tunçel, Candan ve Satır, 2017) üzerine çalışmaların gerçekleştirildiği görülmektedir.

Endüstri 4.0 bağlamında eğitim alanında ülkemizde yapılan çalışmalara (Demir, 2018; Öztemel, 2018; Aybek, 2017; Yazıcı ve Düzkaya, 2016) bakıldığında ise çoğunlukla Eğitim 4.0 ve Üniversite 4.0 kavramları çerçevesinde mevcut eğitim programlarının değişime ne derece hazır olduğunun incelendiği ve oldukça kısıtlı sayıda kaldığı görülmektedir. Üretim süreçlerinde ve rutini tanımlanabilen tüm iş kollarında yapay zekâ ile geliştirilen robotların kullanılacağı bir dönemde toplumun işgücünü oluşturacak olan günümüz K12 ve lisans öğrencilerinin, Endüstri 4.0 dönemine yönelik algılarının belirlenmesi, karar vericilerin alacağı stratejik kararlar için önemli argümanlar sunabilir. Alanyazın incelendiğinde ise bu yönde yeterli düzeyde çalışma olmadığı göze çarpmaktadır. Alanyazındaki boşluğun doldurulmasına katkı sağlayacağı beklenen bu araştırmanın amacı, K12 ve Lisans öğrencilerinin Endüstri 4.0 kavramına ilişkin algılarını metaforlar yardımıyla belirlemektir. Araştırma kapsamında aşağıdaki sorulara cevaplar aranmıştır:

1. K12 öğrencilerin Endüstri 4.0 kavramına ilişkin geliştirdikleri metaforlar nelerdir?

2. Lisans öğrencilerin Endüstri 4.0 kavramına ilişkin geliştirdikleri metaforlar nelerdir?

3. K12 öğrencilerin Endüstri 4.0 kavramına ilişkin algıları nelerdir?

4. Lisans öğrencilerin Endüstri 4.0 kavramına ilişkin algıları nelerdir?

\section{Yöntem}

K12 ve Lisans öğrencilerinin Endüstri 4.0 kavramına ilişkin algılarını metaforlar yardımıyla belirlemeyi amaçlayan bu araştırma nitel araştırma desenlerinden biri olan olgubilim (fenomenoloji) deseni ile yürütülmüştür. Desen, günlük yaşamda farkında olduğumuz, ancak derinlemesine ve ayrıntılı bir anlayışa sahip olmadığımız olguların ortaya çıkarılmasında yaygın olarak kullanılmaktadır (Patton, 2014: Yıldırım ve Şimşek, 2013).

Olgu bilim deseni ile bireylerin belirli bir olguya (fenomene) yönelik algılarını belirlemede metaforlar yaygın olarak kullanılmaktadır. Metaforlar, olgular hakkında düşünceleri yansıtan, onlara yön veren en güçlü zihinsel araçlardan biridir (Saban, 2004). Araştırma 
deseniyle uyumlu olacak şekilde metaforlar, günlük yaşamda farkında olunan ama derinlemesine ve ayrıntılı bir anlayışa sahip olunmayan olguların, bilinen başka olgulara benzetilerek açıklanmasını temele almaktadır. Bu araştırmada da K12 ve Lisans öğrencilerinin Endüstri 4.0 ile ilgili algılarını metaforlar yoluyla belirleyebilmek için olgubilim deseni tercih edilmiştir.

\subsection{Katılımcılar}

Araştırmanın katılımcıları amaçlı örneklem yöntemlerinden ölçüt örnekleme ile belirlenmiştir. Ölçüt örnekleme yönteminde, araştırmaya önceden hazırlanmış bir dizi ölçütü karşılayan katılımcılar dahil edilmektedir (Yıldırım ve Şimşek, 2013). Katılımcılar belirlenirken kullanılan ölçütler, Endüstri 4.0 kavramı hakkında yorum yapabilecek öğrencileri belirleyebilmek için K12 öğrencileri için Muğla II Milli Eğitim Müdürlüğü tarafından gerçekleştirilen "Kodlama ve Robotik Şenliği" etkinliğine katılmak, Lisans öğrencileri için ise üçüncü sınıf öğrencileri olmak olarak belirlenmiştir. Endüstri 4.0 döneminin özellikle iş gücünü ve eğitim sistemini etkileyeceğini öngören çalışmalar bulunması nedeniyle İktisadi ve İdari Bilimler Fakültesi ve Eğitim Fakültesi öğrencileri ölçüt olarak belirlenmiştir. Üçüncü sınıf öğrencilerinin seçilme nedeni ise mezuniyete yakın olmaları ve kendi alanları ve iş imkanları ile ilgili yeterli düzeyde alan bilgisine sahip olmalarıdır.

Araştırma hakkında öncelikle öğrenciler bilgilendirilmiş ve araştırmaya katılımda gönüllülük esas alınmıştır. Araştırmaya 49 K12 ve 90 Lisans öğrencisi olmak üzere toplam 139 öğrenci katılmıştır. Katılımcıların demografik bilgileri Tablo 1'de gösterilmiştir.

Tablo 1. Katılımcıların Demografik Özellikleri

\begin{tabular}{|c|c|c|c|c|}
\hline Tür & SInIf & Kadın & Erkek & Toplam \\
\hline \multirow{6}{*}{ K12 } & 5 & 5 & 4 & 9 \\
\hline & 6 & 4 & 5 & 9 \\
\hline & 7 & 3 & 5 & 8 \\
\hline & 9 & 5 & 4 & 9 \\
\hline & 10 & 4 & 5 & 9 \\
\hline & 11 & 2 & 3 & 5 \\
\hline & & & Toplam & 49 \\
\hline \multirow{5}{*}{ Lisans } & İktisat (3. sınıf) & 19 & 18 & 37 \\
\hline & İşletme (3. sınıf) & 21 & 19 & 40 \\
\hline & Bilgisayar ve Öğ- & 6 & 7 & 13 \\
\hline & retim Teknolojileri & & & \\
\hline & & & Toplam & 90 \\
\hline
\end{tabular}


Hatice Hicret ÖZKOÇ | Halit KARALAR

\subsection{Veri Toplama Araçları}

Araştırmada veri toplamak amacıyla araştırmacılar tarafından geliştirilen bir form kullanılmıştır. Form iki bölümden oluşmaktadır. Birinci bölümde öğrencilerin yaş ve cinsiyet gibi demografik bilgilerinden oluşan sorular yer almıştır. İkinci bölümde ise "Endüstri 4.0 gibidir. Çünkü ." sorusu yer almıştır.

Geliştirilen form ile veri toplamadan önce, öğrencilere Endüstri 4.0 ile ilgili olarak genel bir açıklama yapılmış ve üretim süreçlerinde 3D yazıcıların ve robotların kullanıldığı bir dönem olduğu vurgulanmıştır. Formun cevaplama süresi yaklaşık 15 dakika sürmüştür.

\subsection{Verilerin Analizi}

Araştırmada elde edilen veriler içerik analizi ile analiz edilmiştir. İçerik analizinde, birbirine benzeyen verileri belirli kavramlar ve temalar çerçevesinde bir araya getirmek ve bunları okuyucunun anlayabileceği bir biçimde düzenleyerek yorumlamak amaçlanmaktadır (Yıldırım ve Şimşek, 2013).

Analiz öncesinde K12 ve Lisans öğrencileri tarafından üretilen metaforların, konusu (yani Endüstri 4.0), kaynağı (yani benzetme yapılan olgu), konu ile kaynak arasındaki ilişki (çünkü, ... bölümü) bilgileri bir elektronik tablolama programına girilerek tablolaştırılmıştır. Bu işlem sonucunda K12 ve Lisans öğrencileri için iki ayrı tablo elde edilmiştir. Sonraki aşamada, elde edilen tablolarda metaforun konusu ve kaynağı arasında kurulan mantıksal ilişkiler incelenmiştir. Kaynak ve konu arasında mantıksal ilişki kurulamayan cevaplar analiz kapsamı dışında tutulmuştur. Örneğin bu aşamada K12 düzeyinde bir öğrencinin "Endüstri 4.0 dünyaya benzer çünkü dünya üzerindeki canlılar gibi gerçekçiler" şeklindeki açıklaması, bir Lisans öğrencisinin "Endüstri 4.0 evrak çantasına benzer çünkü ihtiyacımız olan her şeyi orada bulabiliriz" ifadesi araştırmadan çıkarılmıştır. Son olarak tablolarda metafor kaynaklarının frekansları ve yüzdeleri hesaplanmıştır.

Veri analizi NVivo programı aracılığıyla yapıımıştır. Metaforların kaynak ve konu arasında kurulan mantıksal ilişkilerine yönelik olarak açıklamalarda, öğrencilerin kendi ifadeleri kullanılarak NVivo içerisinde in-vivo code'lar oluşturulmuştur. Daha sonra ilişkili kodlar, alt temalar altında toplanmıştır. Yine devamında ilişkili alt temalar, bir tema altında toplanarak, veri analizinde tümevarım yaklaşımı izlenmiştir. Analiz süreci sonunda elde edilen temalar, alt temalar ve kodlar frekans değerleri ile birlikte NVivo'nun sunduğu haritalar (maps) desteği ile görselleştirilmiştir.

\subsection{Güvenilirlik ve Geçerlilik}

Araştırmanın güvenirliğine ilişkin olarak kodlama süreci araştırmacılar tarafından bağımsız olarak yürütülmüş ve süreç sonunda oluşturulan kodların tutarlılığı incelenmiştir. Üzerinde uzlaşılan kod sayısının, toplam uzlaşılan ve uzlaşılamayan kod sayısının toplamı- 
na bölünmesiyle hesaplanan kodlayıcılar arası güvenirlik oranı, \%96 olarak hesaplanmıştır. Bu oranın \%90'dan fazla olması önerilmektedir (Miles ve Huberman, 1994). Ayrıca araştırmada elde edilen sonuçların güvenilirliğini ve geçerliliğini sağlamak için araştırma süreci detaylı açıklanmış, veriler mümkün olduğunca detaylı ve doğrudan alıntılarla sunulmuştur (Yıldırım ve Şimşek, 2013).

\section{Bulgular}

\subsection{K12 Öğrencilerin Endüstri 4.0 Kavramına İlişkin Geliştirdikleri Metaforlar}

Araştırmaya katılan 49 K12 öğrencisi tarafından geçerli 48 metafor üretilmiştir. Üretilen metaforlara ilişkin bilgiler Tablo 2'de sunulmuştur.

Tablo 2. K12 Öğrencileri Tarafından Üretilen Metaforlar

\begin{tabular}{|c|c|c|c|c|c|c|c|c|}
\hline Metafor & $f$ & $\%$ & Metafor & $f$ & $\%$ & Metafor & $f$ & $\%$ \\
\hline \multirow[t]{2}{*}{ İnsan } & 1 & 25.00 & Beyin & 1 & 2.08 & Hayat & 1 & 2.08 \\
\hline & 2 & & & & & & & \\
\hline Gelecek & 5 & 10.42 & $\begin{array}{l}\text { Bilim ada- } \\
\text { mI }\end{array}$ & 1 & 2.08 & Kendim & 1 & 2.08 \\
\hline Dünya & 3 & 6.25 & Bitki & 1 & 2.08 & Kulak ve burun & 1 & 2.08 \\
\hline $\begin{array}{l}\text { İnsan } \\
\text { vücudu }\end{array}$ & 2 & 4.17 & Cyborg & 1 & 2.08 & $\begin{array}{l}\text { Mikroskobik } \\
\text { canlılar }\end{array}$ & 1 & 2.08 \\
\hline Ağaç & 1 & 2.08 & Defter & 1 & 2.08 & Mutluluk & 1 & 2.08 \\
\hline $\begin{array}{l}\text { A. Eins- } \\
\text { tein }\end{array}$ & 1 & 2.08 & Diş & 1 & 2.08 & Oyun & 1 & 2.08 \\
\hline Araba & 1 & 2.08 & Doğa & 1 & 2.08 & Robot & 1 & 2.08 \\
\hline Atatürk & 1 & 2.08 & Evrim & 1 & 2.08 & Rüya & 1 & 2.08 \\
\hline Bağımlılık & 1 & 2.08 & Geyik & 1 & 2.08 & Tarım & 1 & 2.08 \\
\hline Bayrak & 1 & 2.08 & Hayal gücü & 1 & 2.08 & Uzaylı & 1 & 2.08 \\
\hline
\end{tabular}

\subsection{Lisans Öğrencilerin Endüstri 4.0 Kavramına İlişkin Geliştirdikleri Metaforlar}

Araştırmaya katılan 90 Lisans öğrencisi tarafından geçerli 89 metafor üretilmiştir. Üretilen metaforlara ilişkin bilgiler Tablo 3'te sunulmuştur. Tablo 3'te sayfa sınırlılığı nedeniyle sadece 37 metafora yer verilmiştir.

Tablo 3. Lisans Öğrencileri Tarafından Üretilen Metaforlar

\begin{tabular}{lcclcclcc}
\hline \hline \multicolumn{1}{c}{ Metafor } & $f$ & $\%$ & Metafor & $f$ & $\%$ & Metafor & $f$ & $\%$ \\
\hline Barbi bebek & 2 & 2.25 & Araf & 1 & 1.12 & Gizemli kutu & 1 & 1.12 \\
Evren & 2 & 2.25 & Arap atı & 1 & 1.12 & Grip hastalı̆ı & 1 & 1.12 \\
Hırsız & 2 & 2.25 & Ateş & 1 & 1.12 & Güneş & 1 & 1.12 \\
Kontrol & 2 & 2.25 & $\begin{array}{l}\text { Bitkisel } \\
\text { yaşam }\end{array}$ & 1 & 1.12 & Insan & 1 & 1.12 \\
\hline Korku filmi & 2 & 2.25 & Bitmeyen & 1 & 1.12 & Kara kedi & 1 & 1.12
\end{tabular}


Hatice Hicret ÖZKOÇ | Halit KARALAR

\begin{tabular}{|c|c|c|c|c|c|c|c|c|}
\hline & & & yol & & & & & \\
\hline Matrix filmi & 2 & 2.25 & $\begin{array}{l}\text { Darth Va- } \\
\text { der }\end{array}$ & 1 & 1.12 & $\begin{array}{l}\text { Karanlık mad- } \\
\text { de }\end{array}$ & 1 & 1.12 \\
\hline Sigara & 2 & 2.25 & Değişim & 1 & 1.12 & Meteor & 1 & 1.12 \\
\hline Uzay & 2 & 2.25 & Doğa & 1 & 1.12 & Mutluluk & 1 & 1.12 \\
\hline Alkol & 1 & 1.12 & Elon Musk & 1 & 1.12 & Pitbull & 1 & 1.12 \\
\hline Annem & 1 & 1.12 & Gelecek & 1 & 1.12 & Diğerleri & 52 & 58.43 \\
\hline
\end{tabular}

\subsection{K12 Öğrencilerin Endüstri Kavramına İlişkin Algıları}

K12 öğrencilerin Endüstri 4.0 ile ilgili oluşturdukları metaforlarda, konu ile kaynak arasındaki ilişki analizi sonucunda elde edilen temalar, alt temalar ve kodlar Şekil 2'de sunulmuştur. Öğrencilerin Endüstri 4.0'a ilişkin algıları değişim ve özellikler ana temaları altında toplanmaktadır.

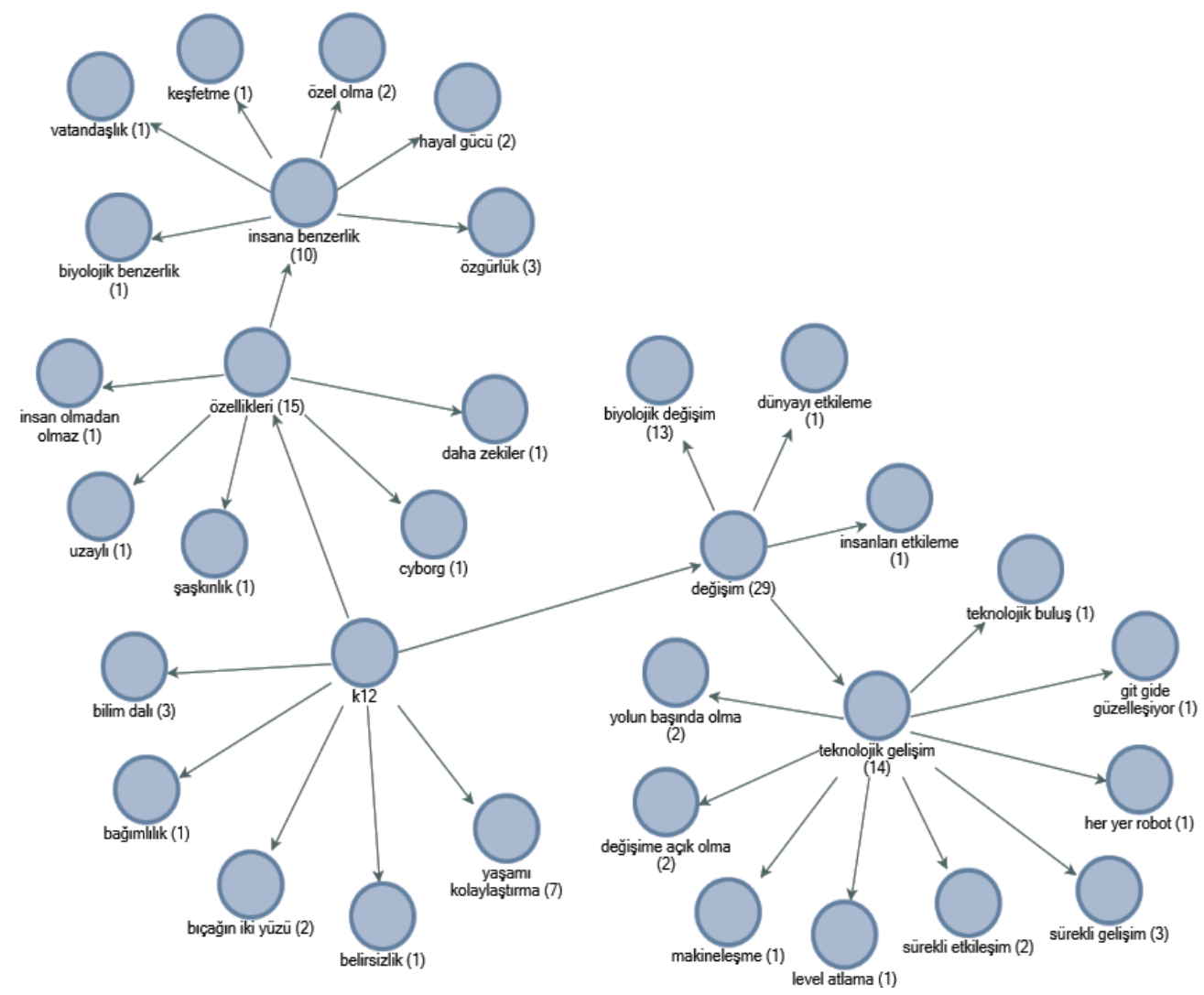


Şekil 2. K12 Öğrencilerin Endüstri 4.0 ile Illgili Algıları

Değişim teması ve teknolojik gelişim alt teması altında öğrenciler tarafından genel olarak Endüstri 4.0 döneminin doğma, büyüme ve ölme gibi doğal bir süreç olduğu, insanları ve dünyayı etkilediği, daha yolun başında olduğu ve sürekli gelişeceği vurgulanmaktadır. Bu yöndeki öğrenci görüşleri, "Artık teknoloji çığır açtı ve her şey çok gelişti. Yapay el, yapay göz yapılabiliyor ve robotların yapamadığı hiçbir şey yok. Arabistan'ın vatandaşlık verdiği robot bile var", "Bu teknolojiler kodlama ile yapıldığı için gelecekte daha çok gelişecek.", "Bu teknolojiler yaşamımızı ve tüm dünyayı etkiliyor.", "Teknoloji geliştikçe daha fazla proje ve fikir ortaya çıkıyor ve sürekli seviye atlayıp daha zor seviyelere ilerliyoruz.", "Mutluluk ve sevinç paylaşıldıkça çoğalır ve artar, yanındakileri de bu sayede etkiler. Yeni gelişen teknolojide aynen böyle yanında olanları da kendine çekiyor ve etkiliyor." şeklindedir.

Özellikler temasının bir alt teması ise insana benzerliktir. Insana benzerlik temasında daha çok Endüstri 4.0 döneminde geliştirilen teknolojilerin özgür düşünce ürünü olacağı, insanların hayalleri ile sınırlı olacağı ve bu teknolojilerin insanlardan daha akıllı olacağı vurgulanmaktadır. Bu yönde öğrenci görüşlerine örnek olarak, "Einstein kendini özgür tutarak buluşlar yapmış ve atomu parçalamıştır. Endüstri 4.0 dönemindeki gelişmeler de özgür ortamlarda geliştirilecektir.", "Insanlar bu teknolojileri hayal ederek başarabiliyor.", "Bu gibi gelişmeler eskiden insanların hayal edemeyeceği düzeydeydi. Şimdi ise bunlar yeni yeni geliştiriliyor ve gittikçe ilerliyor. Önümüzdeki teknolojik gelişmeler ne düzeyde olur kimse bilmez o yüzden bunu hayal gücümüze bırakıyorum." verilebilir.

Öğrencilerin özellikler ve değişim temaları dışında kalan görüşlerinde ise temel vurgu, Endüstri 4.0 döneminin yaşamı kolaylaştıracağı, faydalarının olduğu gibi zararlarının da olabileceği, bu gelişmelerin bilim sayesinde olduğu ve bağımlılık yapabileceği şeklindedir. Bu yöndeki görüşler, "artık insanların yaptığı her şeyi robotlar yapıyor", "bunlar olmadan yaşamımız zorlaşıyor", "bu teknolojiler olmasaydı yaşamımı daha zor olurdu", "iyi işler yapıyorlar ve hayatı kolaylaştırıyorlar", "teknoloji bir bilim dalı ve bilim ve bilim dallarını da ağaca benzetiyorum. Bu bilim dalları sayesinde teknoloji sürekli gelişiyor", "bu teknolojiler sigara ve alkol gibi bağımlılık yapıyor", "bu teknolojiler doğa olayları gibi sonuçları farklı olabiliyor", "bu teknolojilerde insan gibi, insan da bu teknolojiler gibi büyüyüp gelişiyor ve bazen iyi bazen de kötü olabiliyor" şeklindedir.

\subsection{Lisans Öğrencilerin Endüstri Kavramına İlişkin Algıları}

Lisans öğrencilerin Endüstri 4.0 kavramına ilişkin oluşturdukları metaforlarda, konu ile kaynak arasındaki ilişki analizi sonucunda elde edilen temalar, alt temalar ve kodlar Şekil 3'te sunulmuştur. 


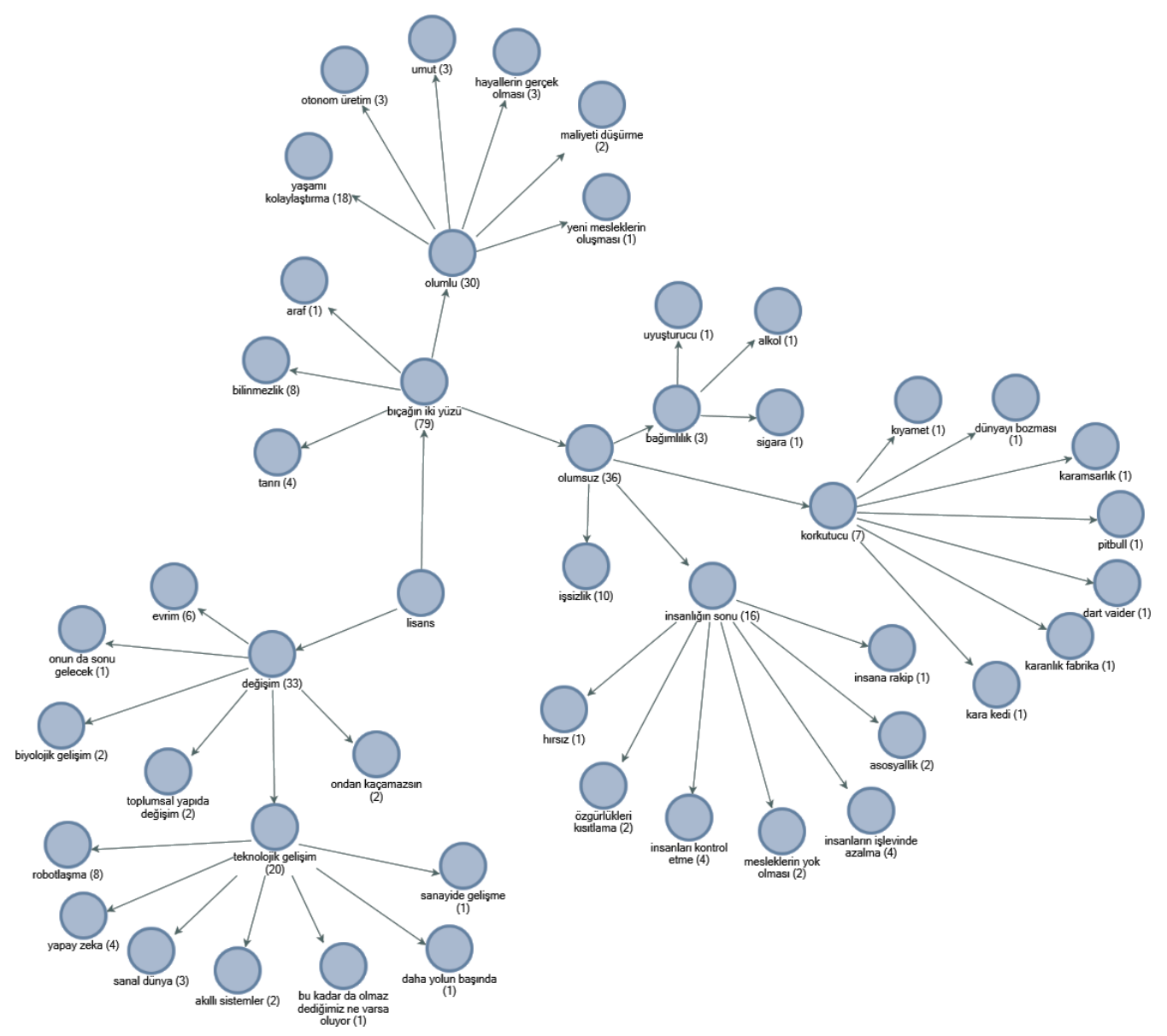

Şekil 3. Lisans Öğrencilerin Endüstri 4.0 ile İlgili Algıları

Öğrencilerin Endüstri 4.0’a ilişkin algıları bıçağın iki yüzü ve değişim ana temaları altında toplanmaktadır. Bıçağın iki yüzü teması, olumlu ve olumsuz görüşleri içeren alt temalardan oluşmaktadır ve olumsuz görüşler daha fazladır. Öğrencilerin açıklamalarında hem olumlu hem de olumsuz düşünceler aynı anda yer alabilmektedir. Bıçağın iki yüzü, tema ismi bu nedenle tercih edilmiştir. Öğrencilerin Endüstri 4.0 dönemi ile ilgili hem olumlu hem de olumsuz görüşlerini içeren ifadelerine örnek olarak, "hiç kimse (Endüstri 4.0'ın) bizlere neler getireceğini ve neleri götürebileceğini bilemez, bu teknolojik gelişim birçok işin yok olmasına ve birçok yeni iş kollarının oluşmasına neden olacaktır.", "gün geçtikçe teknoloji ilerliyor, bu bir yandan iyi gibi görünse de yani minimum insan maksi- 
mum teknoloji ya da minimum gider maksimum verim, insanın yok sayıldığı bir döneme giriliyor", "hayatımızı kolaylaştırıp verimliliği artıracak olsa da bir çok iş̧̧inin işsiz kalmasına neden olacaktır, hayatımızda kullanımları arttıkça insanlar pasif durumda olacaktır", "teknoloji hem iyi hem de kötü olabilir, ileri teknoloji insanı köreltebilir diğer taraftan yaşamı kolaylaştırır", "iyiyle kötünün arasında duruyor, yaşanan gelişmeler insanlığı hem rahata hem de zora, sıkıntıya sokacak niteliktedir", "insanların yaşamını kolaylaştıracak gibi görünse de insanlığın sonunu getirebilecek güçtedir", "hem ülkemiz bu teknolojiyi yakalamakta çok geç kalacak hem de bu kadar istihdam açığı varken otonom üretimle bu sayı çok fazla artacak. Ancak geç kalmayıp ayak uydurabilirsek ülkemizin gelişme sürecine mükemmel katkı sağlayabilir bu da bana heyecan veriyor" verilebilir.

Öğrencilerin Endüstri 4.0 ile ilgili olumsuz görüşleri, işsizlik, bağımlılık ve korkutucu olması alt temaları altında toplanmaktadır. Bu alt temalar ile ilgili öğrenci görüşlerine örnek olarak, "insanlara duyulan ihtiyaç azalacak ve işsizlik artacak", "barbi bebek gibi görüntü olarak her şey çok güzel ama özüne indiğimizde iş gücünü olumsuz etkilenecek ve işsizlik oranı artacak", "hırsız gibi, gelecekte birçok kişinin işini, aşını belki de geleceğini hatta geçmişini elinden alacak", "pitbull cinsi köpek gibi, yavruyken yeni başlarda güzeldir tatı gelir fakat sonradan kontrolden çıkar", "sigara gibidir, zevk ile başlayan ama sonu insanlığı bitirmeye yönelik olan bir terimdir", " yakın zamanda insanlar ruhundan bir şeyler katmadıkları meslekleri yapamayacak hale gelecekler. Insan makinelerden farkını fark etmek zorunda kalacak", "izlediğimiz bilim-kurgu filmler artık gerçekleşmiş durumda, örneğin 'black mirror' bize bu geleceği göstermektedir. Senaryonun genelinde yapay zekanın insanlığı ele geçireceği anlatılır. Bu durumda bizi korkunç bir gelecek bekliyor.", "sanal dünya gibi milyonlarca bilgiye ve donanıma sahiptir, fakat korkutucu bir yönü, insanların işlevi yapay zeka ve robotlar ile kaybolabilir", "fantastik filmlerde karşılaştığımı şeyler günümüzde gerçek oluyor, diğer yandan korku filmi gibi, korku filmlerinde kötü bir şey olacağını hissederiz ama yine de izlemeye devam ederiz", "teknoloji insanları kontrol altına alabilir, bu durumda insanlar nasıl fikir, düşünme, yapma ve gerçekleştirme özgürlüklerine sahip olabilir.", "kurulmuş bir saat sabah sizi kaldırma amacına hizmet eder bu yönüyle iyidir ama kalkmak istemezseniz size rahatsızlık verir, vakti gelince size bunu yapmalısın, şunu yapmalısın diye komutlar veren teknolojiler ne kadar doğru?", "teknoloji geliştikçe insanların normal gündelik yapacağı işleri yapıyor ve gelecek nesillerin yerini alacak gibi duruyor, artık gelecek bizlerin değil robotların" verilebilir.

Öğrencilerin Endüstri 4.0 ile ilgili olumlu görüşlerinde temel vurgu, yaşamı kolaylaştırma, yeni mesleklerin ortaya çıkması, otonom üretim ve maliyetlerin azalması, hayallerin gerçek olmasıdır. Bu yöndeki öğrenci görüşlerine örnek olarak, "teknoloji hayattaki bütün işlerimizi kolaylaştırıp bize destek olabiliyor, çok daha zor olan işleri daha kolay ve mümkün kılıyor", "insanların iş hayatının olumlu etkiler, maliyeti düşürür, seri üretime geçer", "var olandan muhteşem bir dünya yaratır", "teknoloji bize yapay bir dünya sunar, işlerimizi kolaylaştırır", "robotlar bizim onlara verdiğimiz komutlar sayesinde işlevlerini 
Hatice Hicret ÖZKOÇ | Halit KARALAR

yerine getirirler, Endüstri 4.0'da bunlar gibi hayatımızı kolaylaştıracak", "insanlığın hayal ettiklerini gerçeğe dönüşebildiği bir dönemdir", "her şey internet üzerinden kontrol edilebilecek, bir çok makineyi çalıştırmak için işyerinde olmamıza bile gerek kalmayacak", "insanoğlunun yeni bir çağa adım atması yeniden doğmasıdır, bu çağda tüm işlemler robotlar ve makineler tarafından yapılacak, artık insan gücüne ihtiyaç kalmayacak bu da insanoğlunun yeni bir döneme yeni bir hayata başlaması demektir." verilebilir.

Öğrencilerin Endüstri 4.0 ile ilgili görüşlerini içeren ikinci ana tema ise değişimdir. Değişim teması altındaki temel vurgu, Endüstri 4.0 döneminin biyolojik değişim ya da evrim gibi sıradan bir şey olduğu, ondan kaçılamayacağı, toplumsal yapıda değişimlere neden olan bir teknolojik gelişim olduğu yönündedir. Yine öğrencilerin açıklamalarına göre, bu dönemde adından sıkça söz ettirecek olan teknolojiler ise, robotlar, yapay zekâ, sanal dünya ve akıllı sistemlerdir. Öğrencilerin bu yöndeki açıklamaları, "doğa gibidir, sürekli kendini yeniler", "bebek gibidir, durmadan gelişir ve büyür", "sürekli karşımıza yeni şeyler çıkıyor ve bu şeyler sonsuza kadar ilerleyebilir", "sürpriz yumurta gibi, içinden en zaman ne çıkacağı belli olmuyor, teknoloji o kadar hızlı gelişiyor ki bu kadar da olmaz dediğimiz ne varsa oluyor", "bir uzay boşluğu gibi, ne olduğunu nasıl geliştiğini tam olarak bilmiyoruz, sürekli ilerliyor.", "Arap atı gibi, henüz yolun başında ama zaman geçtikçe açılacak ve hız kazanacak", "temelinde robotlar vardır, yapay zeka, 3 boyutlu yazıcı ya da bir varlığın kopyalanması bunlara örnektir.", "dokunmadığı hayat, etki etmediği alan yoktur, ondan kaçamazsınız" şeklindedir.

\section{Tartışma, Sonuç ve Öneriler}

Endüstride yaşanan devrimler toplumsal yapıda dönüşüme neden olmakta, toplumsal yapıdaki dönüşüm de eğitimi yakından etkilemektedir. Tarım toplumundan sanayi topluma geçişle birlikte günümüz okul sisteminin temellerinin atıldığı düşünüldüğünde, Endüstri 4.0 ile birlikte hem toplumsal yapıda hem de eğitimde önemli değişimlerin olacağı kaçınılmazdır. Üretim süreçlerinde ve rutini tanımlanabilen tüm iş kollarında yapay zekâ ile geliştirilen robotların kullanılacağı bir dönemde toplumun işgücünü oluşturacak olan günümüz K12 ve Lisans öğrencilerinin, Endüstri 4.0 dönemine yönelik algılarının belirlenmesi, karar vericilerin alacağı stratejik kararlar için önemli argümanlar sunabilir. Bu bağlamda, araştırmada K12 ve Lisans öğrencilerinin Endüstri 4.0 kavramına ilişkin algılarını metaforlar yardımıyla belirlemek amaçlanmıştır.

Endüstri 4.0 dönemi ile ilgili doğrudan öğrencilerin görüşlerini belirlemeye yönelik yapılan çalışmaya rastlanamamaktadır. Yapılan çalışmalar (Demir, 2018; Öztemel, 2018; Aybek, 2017; Yazıcı ve Düzkaya, 2016) daha çok Eğitim 4.0 ve Üniversite 4.0 kavramları çerçevesinde mevcut eğitim programlarının değişime ne derece hazır olduğunu incelemektedir. Bu nedenle araştırma ilgili alanyazında yapılan ilk çalışmalardan biri olma niteliği taşımaktadır. 
“Üretemezsen Düşünemezsin, Düşünemezsen Üretemezsin” isimli TEDx konuşmasında Selçuk Özdemir'in Howard Gardner'dan aktardığı "çocuklarımızı bilgisayarların ve makinelerin yapamayacağı işleri yapacak şekilde bilgi ve beceri ile donatmazsak, önümüzdeki on yıllarda çocuklarımızı çok zor günler bekliyor" (Özdemir, 2015) görüşünü çok önemsiyoruz. Araştırma bulguları da bu görüşü desteklemektedir. Araştırmada, bahsedilen bilgi ve becerilerle yeterince donatılmayan Lisans öğrencilerinin Endüstri 4.0 dönemi ile ilgili algılarının genel olarak olumsuz olduğu ve kendi geleceklerine yönelik endişe duydukları sonucuna ulaşılmıştır. Diğer taraftan araştırma sonucunda, "Kodlama ve Robotik Şenliği" kapsamında kodlama, robotik, üç boyutlu yazıcılar vb. konularda belirli düzeyde bilgi ve beceri kazanan K12 öğrencilerinin ise Endüstri 4.0’a ilişkin daha olumlu algıya sahip oldukları belirlenmiştir. K12 öğrencileri genel olarak, Endüstri 4.0 dönemindeki teknolojilerin hayatımızın ayrıımaz bir parçası olduğu, yaşam tarzımızı etkileyecekleri, sürekli geliştikleri (level atladıkları) ve yaşamımızı kolaylaştırdıkları görüşündedir. Bu noktada K12 öğrencilerinin almış oldukları eğitimlerin Endüstri 4.0 dönemine ilişkin görüşlerini olumlu yönde etkilediği söylenebilir.

Ülkelerin kalkınmışlık düzeylerini belirleyen ekonomik gelişmeler hali hazırda dijital ekonomi sayesinde yer değiştirmeye başlamıştır. Illk üç endüstri devrimini gelişmiş ülkelere kıyasla geç yakalamış olan Türkiye'nin Endüstri 4.0 sürecini zamanında yakalayabilmesi ve bu süreci yönetebilmesi, küresel rekabette varlığını sürdürebilmesi ve ülkenin sürdürülebilir kalkınmasının sağlanması noktasında büyük önem taşımaktadır (Yazıcı ve Düzkaya, 2016: 52). Sürdürülebilir kalkınmanın sağlanmasında ise teknolojik değişim ve bilişim teknolojileri kullanımı boyutları ile geleceğin yetişkinlerinin şimdiden bu değişen dünyaya hazır hale getirilmeleri ve bu yönde programların hazırlanması gerekmektedir.

Sonuç olarak günümüzdeki pek çok mesleğin gelecekte kaybolacağı, çocukların kendi mesleklerini icat etmek zorunda kalacakları öngörülen, karmaşık ve kompleks bir dönem olan Endüstri 4.0 dönemine çocuklar çok iyi hazırlanmalıdır. Bunun için de şu anda gelişmiş ve gelişmekte olan pek çok ülkenin yaptığı gibi, küçük yaştan hatta okul öncesinden itibaren çocuklara kodlama öğretilmeli ve bu yönde öğretim programlarında gerekli değişiklikler yapılmalıdır. Bu değişiklikler yapılabilirse, geleceğin yaratıcı toplumları için gerekli olacak 21.yy becerileri çocuklara kazandırılabilir. Bu beceriler bilişimle üretim yapabilme, algoritmik düşünme becerisi, problem çözme, iş birliği ile çalışma, iletişim, yaratııılık, bilgi-işlemsel düşünme (computational thinking) becerileri olarak ifade edilebilir. Bahsedilen değişikliklerin yapılamaması ya da geç kalınması halinde, geleceğe ilişkin olumsuz algıya sahip, mutsuz öğrencilerle karşılaşabilir, var olan eğitim sistemimizdeki problemlere yenileri eklenebilir ve daha karmaşık hale gelebilir. Bir başka ifade ile olumsuz algılar, öğrencilerin tutumlarını olumsuz yönde etkileyebilir, tutumlar da olumsuz davranışların sergilenmesine neden olabilir. Diğer taraftan, Endüstri 4.0 sürecinde donanımlı ve güçlü olabilmek için sadece çocukların değil sürekli eğitim politikaları yardımıyla yetişkinlerinde 
Hatice Hicret ÖZKOÇ | Halit KARALAR

bu sürece dahil olmasının sağlanması oldukça önemlidir. Bu noktada tabana yayılmış eğitim politikalarının ivedilikle hayata geçirilmesi önerilmektedir.

\section{Kaynaklar}

Aybek, H. S. Y. (2017). Üniversite 4.0'a geçiş süreci: kavramsal bir yaklaşım. Açıköğretim Uygulamaları ve Araştırmaları Dergisi, 3(2), 164-176

Boston Consulting Group. (2015). Industry 4.0-The future of productivity and growth in manufacturing industries. https://www.bcg.com/publications/2015/engineered_products_project_business_ industry_4_future_productivity_growth_manufacturing_industries.aspx (Erişim tarihi: 12.11.2018)

Bulut, E., ve Akçacı, T. (2017). Endüstri 4.0 ve inovasyon göstergeleri kapsamında Türkiye analizi. ASSAM Uluslararası Hakemli Dergi, 4(7), 55-77

Demir, A. (2018). Endüstri 4.0'dan Eğitim 4.0'a değişen eğitim öğretim paradigmaları. Turkish Studies, 13(15), 147-171

Ekici, G. (2016). Biyoloji öğretmeni adaylarının mikroskop kavramına ilişkin algılarının belirlenmesi: Bir metafor analizi çalışması. Ahi Evran Üniversitesi Kırşehir Eğitim Fakültesi Dergisi (KEFAD), 17(1), 615-636.

Fırat, S. Ü., ve Fırat, O. Z. (2017). Sanayi 4.0 devrimi üzerine karşılaştırmalı bir inceleme: Kavramlar, küresel gelişmeler ve Türkiye. Toprak İşveren Dergisi, 114, 10-23.

Gilchrist, A. (2016). Introducing Industry 4.0. In Industry 4.0 (pp. 195-215). CA: Apress, Berkeley.

Hofmann, E., \& Rüsch, M. (2017). Industry 4.0 and the current status as well as future prospects on logistics. Computers in Industry, 89, 23-34.

Jazdi, N. (2014, May), Cyber physical systems in the context of Industry 4.0. In Automation, Quality and Testing, Robotics, 2014 IEEE International Conference (pp. 14). IEEE.

Jeschke, S., Brecher, C., Meisen, T., Özdemir, D., \& Eschert, T. (2017). Industrial internet of things and cyber manufacturing systems. In Industrial Internet of Things (pp. 3-19). Cham: Springer.

Koca, K. C. (2018). Sanayi 4.0: Türkiye açısından fırsatlar ve tehditler. Sosyoekonomi, 26(36), 245-252.

Lasi, H., Fettke, P., Kemper, H. G., Feld, T., \& Hoffmann, M. (2014). Industry 4.0. Business \& Information Systems Engineering, 6(4), 239-242.

Lin, C. C., \& Yang, J. W. (2018). Cost-efficient deployment of fog computing systems at logistics centers in Industry 4.0. IEEE Transactions on Industrial Informatics, 14(10), $4603-4611$

Miles, M. B., \& Huberman, A. M. (1994). An expanded sourcebook: Qualitative data analysis (2th edition), CA: SAGE Publications, Inc. 
Öcal, F. M., ve Altıntaş, K. (2018). Dördüncü sanayi devriminin emek piyasaları üzerindeki olası etkilerinin incelenmesi ve çözüm önerileri. OPUS Uluslararası Toplum Araştırmaları Dergisi, 8(15), 35-35.

Özdemir, S. (2015, 21 Eylül). Üretemezsen düşünemzsin, düşünemezsen üretemezsin. https://www.youtube.com/watch?v=0417Nq1Cadl (Erişim Tarihi: 17.10.2018)

Özkan, M., Al, A., ve Yavuz, S . (2018). Uluslararası politik ekonomi açısından dördüncü sanayi-endüstri devrimi'nin etkileri ve Türkiye. Siyasal Bilimler Dergisi, 1, 1-30. doi: 10.14782/marusbd.418669

Öztemel, E. (2018). Eğitimde yeni yönelimlerin değerlendirilmesi ve Eğitim 4.0. Üniversite Araştırmaları Dergisi, 1(1), 25-30.

Öztürk, E., ve Koç, K . (2017). Endüstri 4.0 ve mobilya endüstrisi. Ileri Teknoloji Bilimleri Dergisi, 6(3), 786-794.

Patton, M. Q. (2014). Nitel araştırma ve değerlendirme yöntemleri (M. Bütün ve S. B. Demir Çev.). Ankara: Pegem Akademi.

Qi, Q., \&Tao, F. (2018). Digital twin and big data towards smart manufacturing and industry 4.0: 360 degree comparison. IEEE Access, 6, 3585-3593

Saatçi, E. Y. (2017). Girişimcilik 4.0: tarihten Sanayi 4.0'a doğru girişimciler. Maliye Finans Yazilari, 2017(108), 95-112

Saban, A. (2004). Giriş düzeyindeki sınıf öğretmeni adaylarının "öğretmen” kavramına ilişkin ileri sürdükleri metaforlar. Türk Eğitim Bilimleri Dergisi, 2(2), 131-155.

Saldivar, A. A. F., Goh, C., Chen, W. N., \& Li, Y. (2016, July). Self-organizing tool for smart design with predictive customer needs and wants to realize Industry 4.0. In Evolutionary Computation (CEC), 2016 IEEE Congress (pp. 5317-5324). IEEE.

Schwab, K. (2016). Dördüncü sanayi devrimi (Z. Dicleli Çev.). İstanbul: Optimist Yayım Dağıtım.

Soylu, A. (2018). Endüstri 4.0 ve girişimcilikte yeni yaklaşımlar. Pamukkale Üniversitesi Sosyal Bilimler Enstitüsü Dergisi, 32, 43-57.

Theorin, A., Bengtsson, K., Provost, J., Lieder, M., Johnsson, C., Lundholm, T., \& Lennartson, B. (2017). An event-driven manufacturing information system architecture for Industry 4.0. International Journal of Production Research, 55(5), 1297-1311.

Topkaya, Ö. (2016). Dünyada endüstriyel robot sektörü ve çalışma hayatına etkileri. Ataturk University Journal of Economics \& Administrative Sciences, 30(5), 1129-1143.

Tunçel, S., Candan, Z., ve Satır, A. (2017). Mobilya endüstrisinde gelecek vizyonu: Endüstri 4.0. Ileri Teknoloji Bilimleri Dergisi, 6(3), 152-159.

Uygun, T., Göktürk, B., ve Usta, N. (2016). Üniversite öğrencilerinin matematik problemine ilişkin algılarının metafor yoluyla analiz edilmesi. Bartın Üniversitesi Eğitim Fakültesi Dergisi, 5(2), 536-556. 
Wan, J., Tang, S., Hua, Q., Li, D., Liu, C. \& Lloret, J. (2018). Context-aware cloud robotics for material handling in cognitive industrial Internet of Things. IEEE Internet of Things Journal, 5(4), 2272-2281.

Xia, F., Yang, L. T., Wang, L., \& Vinel, A. (2012). Internet of things. International Journal of Communication Systems, 25(9), 1101-1102.

Yazıcı, E., ve Düzkaya, H. (2016). Endüstri devriminde dördüncü dalga ve eğitim: Türkiye dördüncü dalga endüstri devrimine hazır mı?. Eğitim ve Insani Bilimler Dergisi: Teori ve Uygulama, 7(13), 49-88.

Yıldırım, A., ve Şimşek, H. (2013). Sosyal bilimlerde nitel araştırma yöntemleri (9. bs.). Ankara: Seçkin Yayıncılık.

Zheng, P., Sang, Z., Zhong, R. Y., Liu, Y., Liu, C., Mubarok, K., ..., \& Xu, X. (2018). Smart manufacturing systems for Industry 4.0: Conceptual framework, scenarios, and future perspectives. Frontiers of Mechanical Engineering, 13(2), 137-150. 